\title{
The Dynamics of Housing Prices in Malaysia: Findings from Focus Group Discussions
}

\author{
H.N. AuYong ${ }^{1, *}$, C.Y. Yip ${ }^{1}, K . H$. Woo $^{1}$, and A. Senadjki ${ }^{1}$ \\ ${ }^{1}$ Faculty of Business and Finance, Universiti Tunku Abdul Rahman, Kampar, Perak, Malaysia
}

\begin{abstract}
Background of the Research: This study examines the factors influencing housing prices in Malaysia. The study explores qualitatively whether there is housing bubble in Malaysia, and whether the housing prices are associated with changes in construction cost, land cost, compliance cost, housing speculation, and mortgage rate. Methodology: The paper is exploratory in nature. The data were collected via focus group discussions among nine property industry players in Malaysia and were analysed using qualitative research methodology. Main Findings: The study reaches the qualitative outcomes that rising housing prices are mainly due to cost factors and housing speculation but may not necessarily be influenced by mortgage rate. The findings suggest that the residential property market is currently not facing housing bubble issue. However the problem is partly due to PTPTN blacklisted borrowers. Conclusion: It is imperative for the Malaysian government to put in further efforts to control housing prices in order to maintain affordability of homeownership.
\end{abstract}

\section{Introduction}

Bank Negara Malaysia [1] announced that Malaysia's household debt-to-gross domestic product ratio increased to $89.1 \%$ as of 2015 , one of the highest household debts in the region. BNM has also put in place various macro-prudential policies such as BNM limiting loan-to-value ratio to $70 \%$ for the third home financing as reported in TheEdgeProperty.com [2], and increasing real property gain tax to $30 \%$ for sales of real estate within three years to stem real estate market speculation activities since 2014 [3].

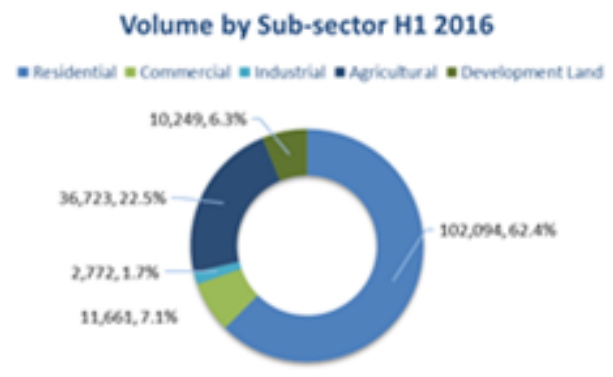

Fig. 1. Volume by Sub-Sector H1 2016 Source: NAPIC (2016b)

According to National Property Information Centre [4], market volume recorded at 362,105 transactions worth RM149.9 billion in 2015 , down by a marginal $5.7 \%$ in volume and $8.0 \%$ in value against 2014 . Residential sub-sector continued to lead the overall market, with $65.2 \%$ contribution in volume and $49.0 \%$ in value. The sub-sector recorded a slight downturn by
$4.6 \%$ in volume and correspondingly down in value by $10.5 \%$.

There were 102,094 transactions worth RM32.70 billion recorded in the review period, a decline of $14.5 \%$ in volume and $10.3 \%$ in value. Performance across the states was subdued. The downtrend (volume transaction) in major states namely Kuala Lumpur ($20.2 \%$ ), Selangor (-14.1\%), Johor (-10.9\%) and Pulau Pinang $(-13.5 \%)$ led to the overall drop in the subsector. Combined, these states formed $49.7 \%$ of the total national residential volume [5].

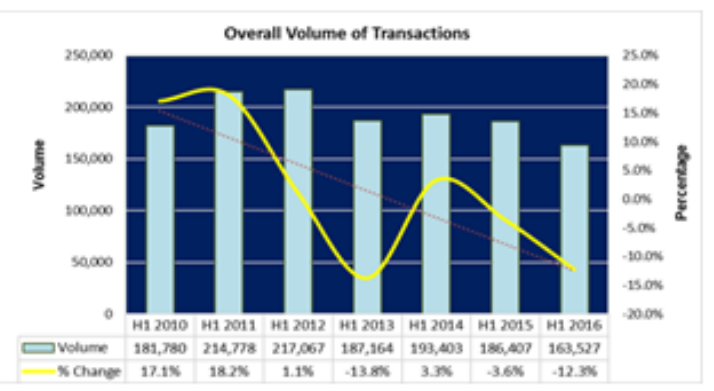

Fig. 2. Overall Volume of Transactions Source: NAPIC (2016b)

According to Khazanah Research Institute (KRI) Making Housing Affordable Report, Malaysian housing market is overpriced as a result of fragmented and inefficient construction business system. KRI has reported that houses in Kuala Lumpur and Penang are "severely unaffordable" and $40 \%$ of the middle income 
groups would need some kind of social housing in the future. The Malaysian all-house price had rose at a compounded annual growth rate (CAGR) of 3.1 per cent from 2000 to 2009. However, between 2009 and 2014, it grew at a CAGR of 10.1 per cent, which was almost three times more than the 2000 to 2009 period [6].

On the other hand, according to Real Estate and Housing Developers" Association (REHDA), properties within the RM200,001 and RM500,000 range are still leading the market [7].

This study explores the current situation of residential property prices in Malaysia based on microeconomic, macroeconomic and financial factors. The continuous upward trend of housing price in Malaysia has raised the attention of home buyers, investors and policy makers. This study is important as it focus on the main factors that affect housing price in Malaysia. These agencies have to treat housing carefully as a significant fluctuation in housing price will affect the wealth of investors and home buyers, as well as the whole country.

\section{Research Method}

\subsection{Description of Focus Groups}

This study is exploratory in nature with a qualitative approach. The data is collected via focus group discussion with nine experts from the property and related industries. Focus group questions were developed by the team of researchers. Focus group discussions were conducted with each group being held in a separate session.

There were two focus group discussions (FGDs) conducted. A focus group panel discussion was held on 13 October 2016 with members:

- Director of an architect consultancy SM

- Senior Project Manager of a holdings company SP Setia

- Chief Marketing Officer of a Property Developer MCT

Another focus group panel discussion was held on 15 October 2016 with members:

- Senior Executive Project Management of a Property Developer SW

- Assistant Manager of a construction and engineering firm FB

- Management staff of a Property Developer SS

- Management staff of a Property Developer GL

- Management staff of a building material firm BS

- Management staff of a Property Developer JH

\subsection{Data Analysis}

Transcriptions of recorded focus-group discussion, lists of facts and views drawn from each group, and individual worksheets are incorporated into the analysis process. This method is applied to create hypotheses that can be tested later by a quantitative survey to be completed by a larger number of participants. For each question, a summary statement will be written to illustrate participants' ideas and viewpoints. A summary report of the key findings will be prepared and reviewed by the researchers as a validity check.

\section{Results and Analysis}

The study analyses the important factors that influence housing prices from information obtained from the participants of the FGD which focus on the following topics.

\subsection{Economic and Housing Market Conditions}

\subsubsection{What is your opinion on the Malaysian economic conditions?}

The responses were mixed. Some said that the condition was not good due to influence of the external economy as well as the internal economic factors. Others have opined that the economic growth was slowed though high inflation made it a good tool to hedge. Yet, some said the condition was reactive, and that market forecast was not accurate while there were also participants with the opinion that the economic condition was positive.

\subsubsection{How would you describe the current state of the housing market?}

Some participants highlighted the effectiveness of the central bank's cooling off policy and the participation of foreign developers from China. Other participants lamented that while there was no control on developer loan, strict control was imposed on house buyer loan. Nevertheless participants shared the view that the situation of financing for developer/homebuyer depends on the location (state) of the projects as well as the type of project, whether low, medium or high end range. Some participants reflected that different state of the market depends on the state governments; overall low range housing market was better than medium to high range market. Other participants expressed that the housing market was slow with high volume of unsold units in the high-end segment.

\subsection{How do the 1990 s and 2010 s scenarios compare in terms of housing bubble?}

The booming property market in the early 1990's collapsed and was followed by the 1997/98 Asian financial crisis. An episode of housing crisis of very much smaller impart recurred in the local market during 2010 following the sub-prime mortgage led housing crisis in the U.S.

Generally, the participants did not think that any housing bubble exists in the domestic market. However it was uncertain of this time with internet marketing. 
There was opinion that the housing industry was much localised, i.e. its issue was not housing bubble but rather more of supply and demand and regulatory policies. One participant said that the situations were incomparable with emerge of internet marketing as new driver of economic growth. Another was of the opinion that Developer Interest Bearing Scheme (DIBS) affected the housing price, and it all depended on risk profile of individual, and interest rate level. Another participant was of the opinion that he had more confidence in 1998 period than the 2010 period.

\subsection{Housing Price}

\subsubsection{In what direction is the housing price moving?}

The participants were divided for the clear direction as they have different opinions on construction and associated costs, types of properties and government institutional factors. Some participants were still confident that prices would increase in certain areas due to higher land cost, construction cost and compliance cost. Some expressed the importance of the government's actions, i.e. institutional factor and how well the government controls public securities and social unrest elements. Other participants expressed view that price still can increase depending on property types, such as Small Office Virtual Office (SOVO) and Small Office Home Office (SOHO) which still remain promising, and these are purchasers having follower behaviour that causes price change.

\subsubsection{Do you expect housing prices to fall rapidly?}

Most participants did not think that the housing prices would fall rapidly. Some stressed that bank credit situation that would determine the price movement. Some said that medium range housing would not drop, but high-end housing (RM2 to 3 million per unit) would be affected. Some predicted that the housing price would stay stagnant for some time but would not decline. Some thought positively that developers nowadays were more adaptive to the market and able to produce houses in line with buyers' needs

\subsubsection{On what factors are you basing your view?}

Some were pessimistic that the price would revise downward $10 \%$ to $25 \%$. Others have mixed views that it all depends on supply and demand, i.e. loan availability to developer and end borrower, with impacts from graduates blacklisted due to PTPTN loan. Some stressed the importance of local content policy i.e. construction material cost. Some were optimistic that the current house offerings seen to be competitive with healthy take-up rate.

\subsection{Housing Price Changes}

\subsubsection{What are the factors that could influence housing prices?}

In general, it was said that it was due to government policy and construction cost. Some said the housing price would not drop while credit approval depended on the government's lending policy. Furthermore, details of the costs were such as land cost, construction cost and compliance cost; the weightage were different from one country to another, e.g. the ratios in Malaysia were 20\%: 70\%: 10\% vs. Singapore's 50\%: 40\%: 10\%. Lower interest rate would reduce the chances of bubble burst, and encourage FDI.

\subsubsection{Has the Malaysian housing market enter into such a volatile situation? What are the significant impacting factors?}

Some participants said that in general, housing bubble was not expected in short-term depending on government policies. Some said that there was no bubble and it was not expected to have one in near future. Another participant concurred that there was not bubble in long-term, depending on confidence (increase in FDI that creating jobs and eventually housing demand). Some participants said that it all depends on the government's check and balance policy (relaxing loan vs. non-performing loan). Another participant said government should decentralise public services as 40 departments involved for approval.

\subsection{How effective have countervailing policies been in stabilising housing prices?}

Over the recent few years of rapid surge in housing prices, the Malaysian government has implemented various policies with the aim to stabilise and check house price hikes. Some said the polices were not effective, while other said that the policies brought the housing prices to fair level, with more people buying for staying rather than for investment, as even PRIMA housing prices were not cheap.

\subsection{Characteristic of the Purchasers}

\subsubsection{Do you see more of first time house buyers during the current period?}

Most participants agreed that more of the buyers were first time house buyers as buying property to preserve value and saving rental cost, though some other still maintained that more of investors. 


\subsubsection{What do you think factors shaping current} trend?

Most FGD participants had different opinions on the determinants, some were not sure of these factors, some mentioned availability of bank loan, speculators, some said foreigner price ceiling, though some insisted buyers would appreciate properties with new trends, designs and features and paying premiums for these properties.

\subsection{Inflow of Capital}

\subsubsection{Do government regulatory control measures affect the elasticity of supply of housing?}

In the past, one of the measures that the authorities have employed in countering housing market volatility is the restriction on the price level of residential properties for foreign buyers. The participants were divided on their opinions. Some said the policy was good to keep restrictions of house prices for foreigners; however others expressed their doubts of its effectiveness due to small percentage of foreign buyers.

\subsubsection{Will liberal inflow of capital have a negative impact on housing prices?}

Some participants expressed their doubts of its importance due to insignificant percentage of foreign buyers. Nevertheless, some other participants thought that it was important to obtain FDI moderately. There were participants who highlighted the better way to attract FDI is to speed-up transaction period such as the transaction would be completed in one week in Hong Kong.

\subsection{Housing Affordability}

\subsubsection{Are the current prices of housing comparable to the purchasing capability of the buyers?}

It has always been widely concerned among the people and the authorities on the affordability of housing. All the participants were of the opinion that the current level of housing price was healthy based on the ratio of house price/income, furthermore, developers were building affordable houses under the PRIMA and Rumah SelangorKu.

\subsection{2 - Are current price levels affordable for respective income groups?}

All participants agreed that the current price levels were barely affordable especially newly launched projects

\subsection{Bank lending}

\subsubsection{Does the previously more relaxed bank loan regulation in dispensing mortgage loans contribute to house prices increase?}

Recent reports have pointed to the tightening of lending by banks and financial institutions as one of the principal reasons affecting the housing market. All participants were of the view that the dispensing of mortgage loans need to be more relaxed, especially for first time house buyers. However the current problem lie with the substantially large number of blacklisted PTPTN borrowers who though within the home buyers age group do not quality for homeloans. Meanwhile, the growth of housing supply has outpaced that of bank financing.

\subsubsection{Do you consider the current housing mortgage rate as too high?}

All participants were of opinion that the mortgage rate was reasonable low and therefore not the major factor affecting housing market.

\subsection{Are there any factors that you will monitor for signs of market overheating?}

Some participants shared the view that overheating signs were such as ads on completed projects and house auctions. Other participants are of the opinion that the Government could control and balance the housing supply through housing industry regulatory measures and financing policies.

\section{Discussion}

The findings of the FGD indicate that speculators, housing demand, land cost, construction material cost, compliance cost and new house features are positively linked with the housing price. On the other hand, the participants agreed that high mortgage rate was not the factor affecting the industry. Another finding reveals that there is inverse relationship between the financing policies and the housing price. All participants thought that there was no housing bubble, and it was unlikely that housing prices would drop further especially the medium range housing, and most of the house buyers were first time buyers.

It is interesting to find that the industry players consistently do not think that affordability is an issue while government agencies such as Khazanah Research Institute, say otherwise. The mortgage rate is reasonably low. The participants highlighted that the current problems lied at blacklisted PTPTN borrowers. The industry players also thought that there was no issue of overheating as the Government could control housing supply and financing policies. 


\section{Conclusion}

The following Information is for either paper type. Every presentation at the conference must have a submission. The conclusion should provide the thoughtful end of the paper which sums up the authors' view and opinion on the subject matter of the paper. In addition, the future development on the findings and the prophecies espoused on future studies may also be highlighted. There is diverse opinion on the main issues of overheating or affordability of housing prices between the Government and the property industry players; while the Government reports that the housing market is overpriced, the industry says that properties within the RM200,001 and RM500,000 range are leading the market and still available in various locations. In this study, data were collected from focus group discussions involving nine property developers and related industry experts. The discussion shows that cost factors are influencing Malaysian housing prices, while mortgage rate is not. In addition, Real Estate and Housing Developers" Association (REHDA) said properties within the RM200,001 and RM500,000 range are still leading the market, with residential properties below RM500,000 still available in various locations. As a result, efforts to increase affordability should be led by the Government housing and financing policies with greater emphasis to maintain housing affordability especially for the younger generation.

\section{References}

1. Bank Negara Malaysia (BNM). Financial Stability and Payment Systems Report 2015. (2016).

2. Bank Negara imposes maximum loan-to-value (LTV) ratio of $70 \%$ for 3rd home loan. TheEdgeProperty.com, 3 November 2010. (2010).

3. Inland Revenue Board (IRB). Real Property Gains Tax. LHDNM/R13/15. (2015)

4. National Property Information Centre (NAPIC). Annual Report 2015. (2016a).

5. National Property Information Centre (NAPIC). First Half Report 2016. (2016b).

6. I. Suraya, I. Nadia, J. P. Marjan, M. M. Making Housing Affordable, (Khazanah Research Institute, Kuala Lumpur, 2015)

7. E. Yeong, REHDA disagrees with Khazanah Institute's Housing Market 'Findings', The Sun Daily - 14 September 2015 (2015) 